\title{
Clinical Characteristics of Alcohol Combined with other Substance Use Disorders in an American Indian Community Sample*
}

\author{
David A. Gilder, Gina M. Stouffer, Philip Lau, and Cindy L. Ehlers ${ }^{\star *}$ \\ Molecular and Cellular Neuroscience Department, The Scripps Research Institute, 10550 North \\ Torrey Pines Road, La Jolla, CA 92037 USA
}

\begin{abstract}
Background-Alcohol and other substance use disorders (SUD) pose major problems of morbidity and mortality in some American Indian communities, but little is known about the clinical characteristics, risk factors, and consequences of combined alcohol and other substance use disorders (multi-substance use disorder, MSUD) in those communities.
\end{abstract}

Methods-Using the Semi-Structured Assessment for the Genetics of Alcoholism (SSAGA), in a community sample of 876 American Indians, the clinical characteristics of lifetime DSM-5 moderate or severe alcohol use disorder alone (AUD alone) ( $\mathrm{n}=146)$ and MSUD (defined as alcohol and $\geq 1$ other SUD) $(n=284)$ were evaluated and compared to 347 participants with no lifetime SUD (no SUD).

Results-The majority (57\%) of participants with a SUD had multi-substance use disorder and 94\% of those were with AUD. Stimulants (cocaine and/or amphetamine) and/or cannabis were the most common other SUDs. Participants with AUD alone were more likely to be male and have an earlier age of first alcohol intoxication than those with no SUD. Those with MSUD were more likely to have dropped out of high school, have antisocial personality disorder (ASPD) or conduct disorder (CD), have earlier ages of first alcohol intoxication and first use of cannabis and stimulants, an earlier age of onset of AUD, and more of several AUD symptoms than those with AUD alone, but the same temporal course and time to remission of AUD.

\footnotetext{
* Supplementary material can be found by accessing the online version of this paper at http://dx.doi.org and by entering doi:...

** Corresponding author at: The Scripps Research Institute, 10550 North Torrey Pines Road, SP30-1501, La Jolla, CA 92037. Tel.: (858) 784-7058; Fax: (858) 784-7409., cindye @ scripps.edu.

Conflicts of Interest

The author(s) declare that they have no conflicts of interests.

Contributors

All authors have given intellectual contributions to the study and the paper and have approved the final manuscript. David A. Gilder and Cindy L. Ehlers were responsible for the study design. Gina M. Stouffer and David A. Gilder were responsible for collecting and coding the clinical data. Dr. David A. Gilder was responsible for making all the best final diagnoses. Philip Lau was responsible for higher level statistical analyses. Gina M. Stouffer, Philip Lau, David A. Gilder and Cindy L. Ehlers were all responsible for the preparation of the manuscript. All authors contributed to and have approved the final manuscript.

Publisher's Disclaimer: This is a PDF file of an unedited manuscript that has been accepted for publication. As a service to our customers we are providing this early version of the manuscript. The manuscript will undergo copyediting, typesetting, and review of the resulting proof before it is published in its final citable form. Please note that during the production process errors may be discovered which could affect the content, and all legal disclaimers that apply to the journal pertain.
} 
Conclusions-MSUD is prevalent in this sample, is associated with multiple comorbidities and denotes a more severe alcohol syndrome than AUD alone.

\section{Keywords}

American Indian; alcohol; multiple substance use disorder; clinical course of alcoholism

\subsection{INTRODUCTION}

National surveys have demonstrated that a large proportion of people using substances are not just using one drug but are using many different drugs, both licit and illicit, both in combination and sequentially (Clayton, 1986; Compton et al., 2007). Therefore, the study of the epidemiology, clinical correlates, and consequences of multidrug use becomes an important public health issue. In multidrug use patterns, the most frequent appears to be those involving alcohol, and alcohol is typically the first substance used over the developmental trajectory of substance use. Although several national surveys have collected epidemiological data on the prevalence and trajectory of multi-substance use, primarily in youth (Conway et al., 2013; Moss et al., 2014), there have been fewer studies that have focused on multi-substance dependence. Data from the National Comorbidity Survey demonstrate that over $30 \%$ of men and women with alcohol dependence also have another drug dependence (Kessler et al., 1997). Moss et al. (2015) have estimated that in the National Epidemiologic Survey on Alcohol and Related Conditions (NESARC) data that a similar percentage $(25.3 \%)$ of those with alcohol dependence used other drugs such as tobacco, cannabis and cocaine, and they had the most severe pattern of alcohol consumption as well as an overrepresentation of other Axis I and Axis II disorders.

There has been less information on how multi-substance use may differentially impact minority communities, particularly in American Indians (Whitesell et al., 2012). American Indians, as a group, have higher rates of alcohol-related morbidity and mortality than many other U.S. ethnic groups (Landen et al., 2014; Indian Health Service, 2009, 2015). The rates of alcohol and other substance use disorders (SUDs) in the small number of tribes studied have been reported to be 2-5 times higher (Ehlers et al., 2004a; Leung et al., 1993; Robin et al., 1998; Spicer et al., 2003) than the epidemiological rates for the U.S. general population (Compton et al., 2007; Grant et al., 2004, 2015; Hasin et al., 2007; Smith et al., 2006). One possible explanation for the higher rates of morbidity and mortality associated with alcohol use disorders (AUDs) in some American Indian communities is that they may have more multi-substance use disorder (MSUD) than the general population.

Two studies of multi-substance use and use disorder in American Indians and Alaska Natives lend support to this hypothesis. In a community sample of 1086 Navajo participants, Kunitz (2008) found that the use of higher numbers of drugs was associated with higher rates of DSM-3R alcohol dependence and more alcohol dependence symptoms. They also found that earlier lifetime first drink was associated with higher levels of drug use. In another study that evaluated 582 Alaska Natives in an inpatient treatment program, it was found that patients with alcohol plus opiate dependence drank more, and had earlier ages of onset of first intoxication, regular drinking, and alcohol dependence than those with alcohol

Drug Alcohol Depend. Author manuscript; available in PMC 2017 April 01. 
plus cocaine or cannabis dependence (Malcolm et al., 2006). While these data suggest that MSUD represents a more severe syndrome than has been reported in the general population (Moss et al., 2010), it is not known whether some populations experience different substance use combinations or other comorbidities and thus whether these data will generalize to other community samples of adult or adolescent American Indians. Knowledge concerning the clinical characteristics of MSUDs within a sample is important in that it may allow more tailored intervention, prevention and treatment programs for that community to be developed.

The present report is part of a larger study exploring risk factors for substance dependence in a community sample of American Indians (Ehlers et al., 2004a, 2008c; Gilder et al., 2004, 2006, 2007, 2009). The lifetime prevalence of substance dependence in this Indian sample is high and genetic and environmental risk factors for substance dependence have been identified (Ehlers and Wilhelmsen, 2005, 2007; Ehlers et al., 2004b, 2006, 2007a, 2007b, 2007c, 2008a, 2008b, 2009, 2010a, 2010b, 2011, 2013; Gizer et al., 2011; Wall et al., 2003; Wilhelmsen and Ehlers, 2005). We have also demonstrated in this population that AUDs have an early age of onset, a rapid and severe clinical course, specific patterns of psychiatric comorbidity, and high rates of remission (Ehlers et al., 2008a; Gilder et al., 2004, 2006, 2008).

Using data from this unique sample, we sought to determine the prevalence of single and multiple substance use disorders. We then investigated the clinical correlates of AUDs with and without one or more other substance use disorders, and examined whether they differed in their demographics, age of onset, comorbidity, clinical course, and tendency to remit.

\subsection{MATERIAL AND METHODS}

\subsection{Participants}

American Indian participants were recruited from eight geographically contiguous rural Indian reservations in Southwest California with a total population of about 1,835 individuals who were American Indian and 18 years of age or older and therefore eligible for the study. Participants were recruited from tribal halls, health clinics, tribal libraries, and stores on the reservations. Flyers advertising the study were posted in each location with the telephone number of the tribal recruitment coordinator, who visited each location regularly and approached potential participants to offer information about and enrollment in the study. Individuals who elected to participate were encouraged to inform other individuals about the study. Transportation from home to The Scripps Research Institute was provided. The protocol for the study was approved by the Institutional Review Board of the Scripps Research Institute, and the Indian Health Council, a tribal review group overseeing health issues for the reservations where recruitment was undertaken. Written informed consent was obtained from each participant after the study was fully explained.

\subsection{Measures}

Each participant completed an interview with the Semi-Structured Assessment for the Genetics of Alcoholism (SSAGA; Bucholz et al., 1994) in order to generate demographic 
variables, lifetime alcohol, cannabis, and stimulant use and use-related symptom variables, and lifetime Diagnostic and Statistical Manual, Fifth Edition (DSM-5; American Psychiatric Association, 2013) use disorder and psychiatric disorder diagnoses. The SSAGA has undergone both reliability and validity testing (Bucholz et al., 1994; Hesselbrock et al., 1999) and has been used in another American Indian sample (Hesselbrock et al., 2000, 2003; Malcolm et al., 2006). All interviews were reviewed and all best final diagnoses (lifetime prevalence) were made by a research psychiatrist/addiction specialist (DAG).

Demographics, substance use information, and symptoms were used to construct variables for the data analyses. A participant's reported Native American Heritage (NAH) was dichotomized as $<50 \%$ vs. $\geq 50 \%$. Years of education were total lifetime years of school attained. Current household income was determined as $<\$ 20 \mathrm{~K}$ vs. $\$ 20 \mathrm{~K}$ per year, current marital status as married vs. not married, and current employment as employed vs. not employed.

Alcohol, cannabis, and stimulant use variables included: (1) age of first intoxication with alcohol, age of first cannabis use, and age of first stimulant use; (2) symptoms associated with use and their ages of onset; and (3) ages of onset of DSM-5 use disorder(s) and of one year full sustained remission from use disorder(s). Thirty-six lifetime alcohol use variables and their ages of onset were also assessed in order to examine the clinical course of alcoholism as previously described (Ehlers et al., 2004a). All stimulant use variables and symptoms were considered positive if a participant used or reported the symptom for cocaine or methamphetamine or both. A participant with $\geq 4$ use disorder criteria for alcohol, cannabis, stimulant, or another substance (including sedative, opioid, phencyclidine, hallucinogen, ecstasy, or solvents) occurring in the same 12-month period during his/her lifetime was diagnosed with the respective lifetime DSM-5 SUD. These use disorders represent the moderate and severe, but not the mild, levels of DSM-5 SUD. Early versions of the SSAGA did not allow for a diagnosis of nicotine use disorders so nicotine dependence was not included. Three diagnostic categories were constructed as follows: no SUD, AUD without any other SUD (AUD alone), and alcohol with one or more additional SUD (MSUD).

The following psychiatric disorder variables were used in the analyses of comorbidity: antisocial personality disorder or conduct disorder (ASPD/CD), which was considered positive if a participant had a lifetime history of conduct disorder (CD) with onset of $\geq 3$ criteria before the age of 15 years or antisocial personality disorder (ASPD); attention deficit hyperactivity disorder (ADHD), defined as having ADHD inattentive type or ADHD hyperactive type; "any affective disorder", which was considered positive if the participant had a lifetime history of major depressive disorder, bipolar I, bipolar II, or dysthymic disorder; and "any anxiety disorder", which was considered positive if the participant had a lifetime history of panic disorder, agoraphobia, or social phobia. All diagnoses were DSM-5 diagnoses with the exception of DSM-IV dysthymic disorder. Remission from alcohol dependence was defined as having no symptom of AUD for $\geq 12$ months at the time of the interview (one year full remission). 


\subsection{Statistical analyses}

The entire original sample consisted of 876 individuals who were $\geq 18$ years old and American Indian. The statistical analyses were focused on 5 aims. The first aim was to describe the prevalence of single SUD and MSUD, and to identify the most common combinations of SUDs. To retain sufficient power to test our 4 remaining aims, subsequent data analysis centered on the 777 (88.7\%) participants from the original sample of 876 individuals who fit into one of three lifetime diagnostic categories: (1) AUD alone; (2) AUD plus at least one other SUD (MSUD); and (3) no SUD. Thus, 99 participants from the original sample of 876 individuals were excluded from subsequent analyses because, although they had a SUD, they did not have AUD. Pearson chi-square and Fisher's exact test for dichotomous variables and ANOVA for continuous variables were used to compare demographic characteristics of the three categories.

The second aim was to determine the pattern of psychiatric comorbidity in the 3 different SUD categories. Rates of each psychiatric disorder in each category were assessed and compared using Pearson chi-square and Fisher's exact test.

To evaluate the third aim, the ages of first intoxication with alcohol, first use of cannabis, first use of stimulants, onset of AUD, onset of cannabis use disorder, and onset of stimulant use disorder were compared in the three categories using ANOVA. To determine the impact of earlier age of first intoxication with alcohol on the development of MSUD in the presence of potential covariates, age of first intoxication with alcohol, age at interview, gender, and all demographic and psychiatric disorder variables that were significantly associated with pairs of diagnostic categories in the first and second aims were entered as independent variables into logistic regression models in which the outcome was each pair of diagnostic categories, MSUD vs. AUD alone, MSUD vs. no SUD, and AUD alone vs. no SUD. Each model was tested for fitness using the Hosmer-Lemeshow Test.

The fourth aim was to estimate the impact of multi-substance use on the clinical course of alcoholism. The clinical course of alcoholism was investigated using the methods described by Schuckit and colleagues $(1993,1995,2002)$ and Ehlers and colleagues (2004a, 2010c) using 36 alcohol-related symptoms derived from the SSAGA. We investigated the differences in endorsement and age of onset of the symptoms in the AUD and MSUD categories. An analysis of how many participants endorsed individual items and whether they differed based on category was undertaken using chi-square. The analysis of whether the age of occurrence of each of the items differed based on category was made using ANOVA. Spearman's rank order correlation (rho) was used to compare the temporal order of age at first occurrence of alcohol-related symptoms in AUD to that in MSUD.

The fifth aim was to investigate the impact of MSUD on remission from AUD. To achieve this aim, we compared rates of remission and also compared time to remission from AUD in the two categories (MSUD, AUD alone) using Kaplan-Meier survival analysis in the presence of censored cases.

All of the analyses described above were carried out using SPSS software (IBM SPSS Statistics for Macintosh, Version 20.0, Armonk, NY). In all analyses the alpha level (2- 
tailed) was set at 0.01 , and p-values were considered significant at $<0.01$ to control for multiple comparisons with a few exceptions. In comparisons of symptom frequencies and ages of onset in the clinical course of alcoholism and the temporal order of AUD symptoms (fourth aim), the alpha level (2-tailed) was set at 0.001 and p-values were considered significant if $<0.001$ to control for multiple comparisons. In the logistic regression analyses (third aim) and in the comparison of the AUD alone and MSUD categories for rates of remission and survival analysis (fifth aim), the alpha level (2-tailed) was set at 0.05 and pvalues were considered significant if $<0.05$.

Power analyses were undertaken for all statistical tests to assess whether the sample size was sufficient for each analysis using $\mathrm{G}^{*}$ Power (Heinrich Heine University, G*Power version 3.1.9.2 for Mac OSX, Düsseldorf, Germany; see also Faul et al., 2007, 2009) for all power analyses except the Spearman rank order correlation and the Kaplan-Meier survival power analyses, which were conducted using website software programs Statistics Solutions Pro (Statistics Solutions Professional, Version 1.14.12.29, Clearwater FL) and StatsToDo (StatsToDo Trading Pty Ltd, Brisbane, Queensland, AU), respectively. Sample sizes were sufficient to provide adequate power with two exceptions: the logistic regression analysis of AUD alone vs. MSUD ( $n=439$ required, $n=430$ obtained) and Spearman rank order correlation of temporal progression of AUD symptoms in AUD alone vs. MSUD ( $n=193$ required, $\mathrm{n}=36$ obtained).

\subsection{RESULTS}

\subsection{Sample description}

We recruited a total of 876 participants who were $\geq 18$ years old and American Indian for a cross-sectional study. These subjects were recruited May, 1995 to June, 2014. All participants were fluent in English.

In this community sample of 876 participants, 284 (32.4\%) had MSUD, 146 (16.7\%) had AUD alone, and 347 (39.6\%) had no SUD. Eighty participants had only one non-alcohol SUD (cannabis only $n=28$, stimulants only $n=50$, opioids only $n=1$, solvents only $n=1$ ). Nineteen participants had two SUDs other than alcohol (cannabis plus cocaine $\mathrm{n}=17$, cocaine plus opioids $n=2)$. Thus, $99(11.3 \%)$ of the original sample of 876 participants had one or more non-alcohol SUD but no AUD. These individuals were excluded from further analysis. The types of multi-substance use disorders that comprised the MSUD category were: 53 (18.7\%) had alcohol and cannabis use disorder alone (i.e. with no other SUD); 92 (32.4\%) had alcohol and stimulant use disorder alone; 78 (27.5\%) had alcohol, cannabis and stimulant use disorder alone; 38 (13.4\%) had alcohol, cannabis, stimulant and one or more other SUD; and $23(8.1 \%)$ had alcohol and one or more other SUD in combination.

\subsection{Demographic and psychiatric variables}

Demographic and psychiatric disorder variables and their comparisons between MSUD, AUD alone, and no SUD are shown in Table 1 and Table 2, respectively. Participants with AUD alone were more likely to be male than those with no SUD, $\chi^{2}(1)=7.9, p=.006$. Participants with MSUD had fewer years of education, $F(1,629)=20.2$, $p<.001$; were more 
likely to be male, $\chi^{2}(1)=9.0, \mathrm{p}=.003$; have an annual household income less than $\$ 20 \mathrm{~K}$, $\chi^{2}(1)=8.6, p=.003$; have dropped out of high school, $\chi^{2}(1)=24.8, p<.001$; have any affective disorder, $\chi^{2}(1)=8.3, \mathrm{p}=.005$; have ASPD/CD, $\chi^{2}(1)=58.7, \mathrm{p}<.001$; and have ADHD, $\chi^{2}(1)=19.1, p<.001$ than those with no SUD. Participants with MSUD had fewer years of education, $\mathrm{F}(1,428)=11.4, \mathrm{p}=.001$; were more likely to have dropped out of high school, $\chi^{2}(1)=14.2, p<.001$; and more likely to have an ASPD/CD diagnosis, $\chi^{2}(1)=15.6, p<.001$, than those with AUD alone. No other difference between categories for demographic variables or psychiatric diagnoses was found.

\subsection{Substance use and dependence variables}

Age of first intoxication with alcohol, age of first use of cannabis, age of first use of stimulants, and ages of onset of AUD, cannabis use disorder, and stimulant use disorder and their comparisons are shown in Table 3. Compared to no SUD, MSUD had an earlier age of first alcohol intoxication, $F(1,565)=139.8$, $p<.001$; first cannabis use, $F(1,534)=47.7$, $p<$. 001 ; and first stimulant use, $\mathrm{F}(1,348)=8.0, \mathrm{p}=.005$. Compared to AUD alone, MSUD had an earlier age of first alcohol intoxication, $\mathrm{F}(1,426)=16.2$, $\mathrm{p}<.001$; first cannabis use, $\mathrm{F}(1$, $406)=24.9, \mathrm{p}<.001$; first stimulant use, $\mathrm{F}(1,332)=7.3$, $\mathrm{p}=.007$; and onset of AUD, $\mathrm{F}(1$, $428)=12.4, p<.001$. Compared to no SUD, AUD alone had an earlier age of first intoxication, $\mathrm{F}(1,429)=28.6, \mathrm{p}<.001$, but was not different on any other variable. In the MSUD category, the mean age onset of cannabis use disorder was 17.4 years (S.E. $=0.4$ ) and the mean age onset of stimulant use disorder was 20.5 years $($ S.E. $=0.5$ ).

Logistic regression analyses were conducted for the three outcomes (MSUD vs. AUD alone, MSUD vs. no SUD, AUD alone vs. no SUD) and examined the association (OR, p-value) with age at first intoxication in the presence of the demographic and psychiatric independent variables that were significant for each outcome in the univariate comparisons described previously. Earlier age of first intoxication was significantly associated with MSUD compared to AUD alone ( $\mathrm{OR}=1.12, \mathrm{p}=0.002)$, with MSUD compared to no $\mathrm{SUD}$ ( $\mathrm{OR}=1.49$, $\mathrm{p}<0.001)$, and with AUD alone compared to no SUD (OR=1.20, $\mathrm{p}<0.001)$. HosmerLemeshow tests indicated that each regression showed good model fit: for the comparison of MSUD and AUD alone, $\mathrm{p}=0.118$; for the comparison of MSUD and no SUD, $\mathrm{p}=0.679$; for the comparison of AUD alone and no SUD, $\mathrm{p}=0.347$.

\subsection{Clinical course of alcoholism}

A comparison of 36 alcohol-related life experiences and their occurrence in time was made between those individuals in the MSUD and AUD alone categories. A high level of similarity was observed between the two categories (MSUD vs. AUD) in the temporal sequence of the progression of problems (Spearman's rho=0.914, $\mathrm{p}<.0001$ )

However, the numbers of persons endorsing individual alcohol-related life problems were found to be different between the two categories. A comparison of the endorsement levels of the individual alcohol-related life events revealed that participants with MSUD were significantly more likely than those with AUD alone to report that their alcohol use was associated with the following nine problems: "drinking just after getting up in the morning," $\chi^{2}(1)=13.5, p<.001$; "inability to change drinking behavior," $\chi^{2}(1)=19.6, p<.001$; "benders 
for $\geq 2$ days," $\chi^{2}(1)=21.9, p<.001$; "problems with work or school," $\chi^{2}(1)=16.0, p<.001$; "giving up important activities," $\chi^{2}(1)=18.2, p<.001$; "craving," $\chi^{2}(1)=12.2, p<.001$; "spent several days recovering from drinking," $\chi^{2}(1)=24.0, p<.001$; "physical fights," $\chi^{2}(1)=21.1$, $\mathrm{p}<.001$; and "hit or threw things," $\chi^{2}(1)=14.9, \mathrm{p}<.001$. Participants with MSUD did not have significantly earlier ages of first occurrence of any alcohol-related symptom than those with AUD alone.

\subsection{Remission}

The rates of one-year full remission from AUD in the MSUD category (46.8\%) and the AUD alone category $(47.3 \%)$ were not significantly different, $\chi^{2}(1)=.01, p=1.00$. When survival times from onset of AUD to onset of one year full remission were assessed using Kaplan-Meier survival analysis, MSUD (Mean=17.7 years, S.E=1.2) and AUD alone (Mean=14.5 years, S.E. $=1.2)$ were not found to be significantly different $\left(\chi^{2}=1.4, p=0.24\right)$.

\subsection{DISCUSSION}

Data from large surveys of drug use in the United States suggest that most substance users cannot be categorically labeled as using a single drug, but rather they may be overinvolved in a primary substance of choice and also using a variety of others (Clayton, 1986; Conway et al., 2013; Moss et al., 2014). It has been suggested from a review of a number of studies that the most common polydrug pattern is with alcohol (Clayton, 1986). In the present study the majority of those participants with a SUD had a multi-substance use disorder and almost all of those were with AUD. Stimulants and/or cannabis were the most common other comorbid SUD with AUD. Of those individuals who had a single SUD, a substantial proportion had only AUD (65\%) and no other SUD, whereas only $12 \%$ had a diagnosis of cannabis use disorder only, $22 \%$ had a diagnosis of stimulant use disorder only, and just one individual had opiate use disorder only. These data are consistent with the notion that in the high-risk population from which this sample was drawn, having a single SUD other than AUD alone is relatively rare.

In this American Indian community sample, MSUD as compared to AUD alone and no SUD, was significantly different on several demographic and psychiatric comorbidity characteristics. The three variables which distinguished MSUD both from AUD alone and from no SUD - fewer years of education, being a high school dropout, and having ASPD/CD - are consistent with the literature from other populations showing a graded, and probably reciprocal, relationship between alcohol and other substance use on the one hand and the development of failure in high school (Grant et al., 2015; Townsend et al., 2007) and ASPD/CD on the other (Compton et al., 2005; Goldstein et al., 2007; Grant et al., 2015; Moss et al., 2007, 2010). While the difference in years of education is statistically significant between MSUD and both AUD alone and no SUD, that 0.5 year difference may not be clinically significant. However, both dropping out of high school (Sum et al., 2009) and ASPD (Goldstein et al., 2008, 2012) are associated with a variety of psychosocial and medical liabilities in adulthood in other samples and are, we believe, clinically significant in this sample. The graded relationship of substance use and poor outcomes with AUD and more strongly with MSUD further suggests that MSUD is a more serious illness than AUD 
alone. That these morbidities evolve together in a mutually reinforcing way beginning in adolescence also points to the importance of developing programs designed to reduce high school failure, the development of ASPD/CD, and alcohol and other substance use for youth in junior high and high school.

MSUD, but not AUD alone, was also associated with having a significantly higher rate of "any affective disorder" than no SUD. Further studies are needed to determine whether or not a similar association of affective disorder with MSUD, but not AUD alone, is seen in other American Indian groups, other ethnicities, or the general U.S. population.

The mean ages of first intoxication with alcohol, first use of cannabis, and first use of stimulants were found to be significantly earlier in the MSUD category than in both the AUD alone and the no SUD categories. Age of first intoxication with alcohol occurred progressively earlier in MSUD, AUD alone, and no SUD. In MSUD, first intoxication with alcohol and first use of cannabis both occurred at a mean age of 13.8 (S.E. $=0.2$ ) years, in early adolescence. First use of stimulants occurred at a mean age of 18.1 (S.E.=0.4) years. Early ages of first intoxication and use are associated with high rates of lifetime AUD, cannabis use disorder, and stimulant use disorder, respectively, in this sample (Ehlers et al., 2006, 2007a; Gilder et al., 2014), in another American Indian sample (Stanley et al., 2014), in samples in other ethnicities (Chen et al., 2009; Ehlers et al., 2010d; Swift et al., 2008), and in the general U.S. population (Dawson et al., 2008; Hingson et al., 2006; Moss et al., 2014; Wu and Schlenger, 2003). The finding that very early age of first intoxication with alcohol is associated with a more severe AUD syndrome is also consistent with Moss and colleagues (2010) findings in their cluster analysis of the NESARC sample that early use of alcohol is associated with more severe clusters of AUD.

The reason(s) for this association of very early first alcohol intoxication with MSUD are poorly understood. Early first intoxication and multiple substance use undoubtedly arises due to a combination of risk factors such as increased genetic risk for externalizing disorders, exposure to key psychosocial risks such as economic disadvantage or heavy substance using peers, and/or may arise from neuropharmacological changes in the developing adolescent brain caused by early alcohol and drug exposure (Spear and Swartzwelder, 2014). In order to identify the mechanisms that may link early age of first intoxication to the development of MSUD, a comprehensive program of longitudinal studies of genetic, psychological and psychosocial risk factors in youth will be required. In the meantime, identifying prevention and treatment options that target early adolescent alcohol, cannabis and stimulant use may not only reduce substance-related morbidity in adolescence, but also reduce rates of SUDs in adulthood.

We found that the clinical course of alcoholism in MSUD as compared to AUD alone was more severe in that nine alcohol-related symptoms occurred more frequently (including craving, problems at school or work, giving up important activities, physical fights, and inability to change drinking behavior) in MSUD. These associations point to significantly increased psychosocial morbidity associated with MSUD in this sample, which is consistent with findings from a nationally representative sample (Grant et al., 2015; Moss et al., 2010). However, the temporal order of the occurrence of the alcohol related symptoms was found 
to be highly correlated between participants with MSUD and those with AUD alone. This suggests that individuals with AUD with or without another SUD have the same clinical course of alcoholism. Analysis of a previous subset of the sample used in the present study (Ehlers et al., 2004a) has shown that AUD examined irrespective of whether it co-occurred with another SUD has the same temporal order of symptoms as several other predominantly EuroAmerican samples (Ehlers et al., 2010c; Schuckit et al., 1993). Similar findings have also been demonstrated in African Americans (Scott et al., 2008) and Mexican Americans (Ehlers et al., 2015). These findings, taken together, indicate fundamental similarities in the development and presentation of AUD in different ethnicities whether or not it is comorbid with another SUD.

When MSUD and AUD alone were combined, one year full remission from DSM-5 moderate or severe AUD in this sample occurred at a rate of $46.9 \%$, which is similar to the rate in a nationally representative all-ethnicity sample of remission from DSM-IV alcohol dependence of $47.7 \%$ (Dawson et al., 2005). In this sample, proportions of those who remitted and survival times from onset of AUD to remission in MSUD as compared to AUD alone were not significantly different. These findings show that substantial remission occurs in both MSUD and AUD alone and raises the hope that rates of remission can be increased with effective intervention and prevention strategies in MSUD as well as AUD alone.

\subsection{Limitations}

The results of this study should be interpreted in light of several limitations. Our sample was demographically different from available Census data for the 8 reservation communities from which we recruited that sample (U.S. Census Bureau, 2010a, 2010b). Compared to the 2010 Census and American Community Survey data, our sample had significantly lower proportions of participants who were: male, married, and employed; and higher proportions of participants who had dropped out of high school and had an annual household income < $\$ 20 \mathrm{~K}$. Proportions of participants with each demographic variable and their comparisons in the two samples are shown in Supplemental Table $1^{1}$. Because the Census data, as well as this sample, may not be representative of the population under study, it is impossible for us to determine whether and to what extent our sample reflects the true demographic and substance use characteristics of that population. Our sample is a sample of convenience and therefore may not be replicable. If we recruited a sample with a greater likelihood of having AUD and other SUDs, our results would be biased in indicating higher rates of SUDs and different characteristics of those SUDs than are actually true for that population. Although similar community samples of American Indian reservation populations (Kunitz, 2008; Leung et al., 1993; Robin et al., 1998) have recorded similar rates of AUD, one reservationbased epidemiologic study (Beals et al., 2005; Spicer et al., 2003) recorded lower rates in two tribes. Therefore, our findings may not generalize to other American Indians in the population from which the sample was drawn. Our findings may not generalize to other tribes living in the general geographic area from which the current sample was drawn, or to other American Indian tribes.

\footnotetext{
${ }^{1}$ Supplementary material can be found by accessing the online version of this paper at http://dx.doi.org and by entering doi:...
} 
Our study examined MSUD defined as AUD plus one or more other SUD. Because MSUD excluded multi-substance use disorders which did not include AUD, our results are different from what they would be if we had examined a different variable, Any MSUD, defined as one or more SUD with or without AUD. To assess whether our results would be different, we repeated the analyses in Tables $1-3$ using Any MSUD $(n=303)$ in the place of MSUD. The results, shown in Supplemental Tables $2-4$, are similar to those of MSUD in Tables 1 -3 , and the statistically significant findings remained the same. Another potential limitation of our study is the use of the variable Native American Heritage ( $<50 \%$ vs. $250 \%$ ). This is a participant self-report variable and may not correlate with other psychosocial or biological variables in the population from which the sample for this study was drawn. We used crosssectional and retrospective data; longitudinal studies may identify different risk variables for the disorders. Additionally, the finding of no difference in the analysis of the temporal progression of AUD symptoms in the comparison of MSUD and AUD alone may be the result of power too low to detect a difference.

\subsection{Conclusions}

In this sample, MSUD is more prevalent than single SUDs. MSUD is most commonly a combination of AUD plus one other SUD (cannabis and stimulants). MSUD is associated with an earlier age of onset of substance use, a more severe alcohol syndrome, and greater psychosocial and psychiatric comorbidity. However, MSUD is not associated with lower chances of remission from AUD. Efforts to understand and prevent the causes of AUD in combination with other SUDs in American Indian communities may be important to reducing the morbidity and mortality associated with overuse of alcohol and other drugs in these high-risk populations.

\section{Supplementary Material}

Refer to Web version on PubMed Central for supplementary material.

\section{Acknowledgements}

The authors wish to acknowledge the technical support of Corinne Kim, Evelyn Phillips, and Derek Wills for assistance in data collection and analysis, and Shirley Sanchez for assistance in manuscript editing.

Role of Funding Source

Funding for this study was provided by grants from the National Institutes of Health (NIH), the National Institute on Alcoholism and Alcohol Abuse (NIAAA) 5R37 AA010201 (CRAN supplement), and the National Institute of Drug Abuse (NIDA) 5 R01 DA030976 (CLE). NIAAA and NIDA had no further role in study design; in the collection, analysis and interpretation of data; in the writing of the report; or in the decision to submit the paper for publication.

\section{REFERENCES}

American Psychiatric Association. Diagnostic and Statistical Manual of Mental Disorders (DSM-5). Fifth ed. American Psychiatric Publishing; Washington, DC: 2013.

Beals J, Novins DK, Whitesell NR, Spicer P, Mitchell CM, Manson SM. Prevalence of mental disorders and utilization of mental health services in two American Indian reservation populations: mental health disparities in a national context. Am. J. Psychol. 2005; 162:1723-1732. 
Bucholz KK, Cadoret R, Cloninger CR, Dinwiddie SH, Hesselbrock VM, Nurnberger JI Jr. Reich T, Schmidt I, Schuckit MA. A new, semi-structured psychiatric interview for use in genetic linkage studies: a report on the reliability of the SSAGA. J. Stud. Alcohol. 1994; 55:149-158. [PubMed: 8189735]

Chen CY, Storr CL, Anthony JC. Early-onset drug use and risk for drug dependence problems. Addict. Behav. 2009; 34:319-322. [PubMed: 19022584]

Clayton RR. Multiple drug use. Epidemiology, correlates, and consequences. Rec. Dev. Alcohol. 1986; 4:7-38.

Compton WM, Conway KP, Stinson FS, Colliver JD, Grant BF. Prevalence, correlates, and comorbidity of DSM-IV antisocial personality syndromes and alcohol and specific drug use disorders in the United States: results from the national epidemiologic survey on alcohol and related conditions. J. Clin. Psychiatry. 2005; 66:677-685. [PubMed: 15960559]

Compton WM, Thomas YF, Stinson FS, Grant BF. Prevalence, correlates, disability, and comorbidity of DSM-IV drug abuse and dependence in the United States: results from the national epidemiologic survey on alcohol and related conditions. Arch. Gen. Psychiatry. 2007; 64:566-576. [PubMed: 17485608]

Conway KP, Vullo GC, Nichter B, Wang J, Compton WM, Iannotti RJ, Simons-Morton B. Prevalence and patterns of polysubstance use in a nationally representative sample of 10th graders in the United States. J. Adolesc. Health. 2013; 52:716-723. [PubMed: 23465320]

Dawson DA, Goldstein RB, Chou SP, Ruan WJ, Grant BF. Age at first drink and the first incidence of adult-onset DSM-IV alcohol use disorders. Alcohol. Clin. Exp. Res. 2008; 32:2149-2160. [PubMed: 18828796]

Dawson DA, Grant BF, Stinson FS, Chou PS, Huang B, Ruan WJ. Recovery from DSM-IV alcohol dependence: United States, 2001-2002. Addiction. 2005; 100:281-292. [PubMed: 15733237]

Ehlers CL, Gilder DA, Wall TL, Phillips E, Feiler H, Wilhelmsen KC. Genomic screen for loci associated with alcohol dependence in Mission Indians. Am. J. Med. Genet. B. Neuropsychiatr. Genet. 2004b; 129B:110-115. [PubMed: 15274051]

Ehlers CL, Gilder DA, Slutske WS, Lind PA, Wilhelmsen KC. Externalizing disorders in American Indians: Comorbidity and a genome wide linkage analysis. Am. J. Med. Genet. B Neuropsychiatr. Genet. 2008a; 147B:690-698. [PubMed: 18286631]

Ehlers CL, Gilder DA, Phillips E. P3 components of the event-related potential and marijuana dependence in Southwest California Indians. Addict. Biol. 2008c; 13:130-142. [PubMed: 18201292]

Ehlers CL, Gilder DA, Gizer IR, Wilhelmsen KC. Heritability and a genome-wide linkage analysis of a Type II/B cluster construct for cannabis dependence in an American Indian community. Addict. Biol. 2009; 14:338-348. [PubMed: 19413562]

Ehlers CL, Gizer IR, Vieten C, Gilder DA, Stouffer GM, Lau P, Wilhelmsen KC. Cannabis dependence in the San Francisco Family Study: age of onset of use, DSM-IV symptoms, withdrawal, and heritability. Addict. Behav. 2010d; 35:102-110. [PubMed: 19818563]

Ehlers CL, Gizer IR, Vieten C, Wilhelmsen KC. Linkage analyses of cannabis dependence, craving, and withdrawal in the San Francisco family study. Am. J. Med. Genet. B Neuropsychiatr. Genet. 2010a; 153B:802-811. [PubMed: 19937978]

Ehlers CL, Gizer IR, Vieten C, Gilder A, Gilder DA, Stouffer GM, Lau P, Wilhelmsen KC. Age at regular drinking, clinical course, and heritability of alcohol dependence in the San Francisco family study: a gender analysis. Am. J. Addict. 2010c; 19:101-110. [PubMed: 20163381]

Ehlers CL, Gizer IR, Gilder DA, Wilhelmsen KC. Linkage analyses of stimulant dependence, craving, and heavy use in American Indians. Am. J. Med. Genet. B Neuropsychiatr. Genet. 2011; 156B: 772-780. [PubMed: 21812097]

Ehlers CL, Gizer IR, Gilder DA, Yehuda R. Lifetime history of traumatic events in an American Indian community sample: heritability and relation to substance dependence, affective disorder, conduct disorder and PTSD. J. Psychiatr. Res. 2013; 47:155-161. [PubMed: 23102628]

Ehlers CL, Lind PA, Wilhelmsen KC. Association between single nucleotide polymorphisms in the mu opioid receptor gene (OPRM1) and self-reported responses to alcohol in American Indians. BMC Med. Genet. 2008b; 9:35. [PubMed: 18433502] 
Ehlers CL, Phillips E, Finnerman G, Gilder D, Lau P, Criado J. P3 components and adolescent binge drinking in Southwest California Indians. Neurotoxicol. Teratol. 2007b; 29:153-163. [PubMed: 17196788]

Ehlers CL, Phillips E, Gizer IR, Gilder DA, Wilhelmsen KC. EEG spectral phenotypes: Heritability and association with marijuana and alcohol dependence in an American Indian community study. Drug Alcohol Depend. 2010b; 106:101-110. [PubMed: 19748744]

Ehlers CL, Slutske WS, Gilder DA, Lau P, Wilhelmsen KC. Age at first intoxication and alcohol use disorders in Southwest California Indians. Alcohol. Clin. Exp. Res. 2006; 30:1856-1865. [PubMed: 17067349]

Ehlers CL, Slutske WS, Gilder DA, Lau P. Age of first marijuana use and the occurrence of marijuana use disorders in Southwest California Indians. Pharmacol. Biochem. Behav. 2007a; 86:290-296. [PubMed: 16930685]

Ehlers CL, Stouffer GM, Corey L, Gilder DA. The clinical course of DSM-5 alcohol use disorders in young adult Native and Mexican Americans. Am. J. Addict. 201510.1111/ajad.12290

Ehlers CL, Wall TL, Betancourt M, Gilder DA. The clinical course of alcoholism in 243 Mission Indians. Am. J. Psychiatry. 2004a; 161:1204-1210. [PubMed: 15229052]

Ehlers CL, Wall TL, Corey L, Lau P, Gilder DA, Wilhelmsen K. Heritability of illicit drug use and transition to dependence in Southwest California Indians. Psychiatr. Genet. 2007c; 17:171-176. [PubMed: 17417061]

Ehlers CL, Wilhelmsen KC. Genomic scan for alcohol craving in Mission Indians. Psychiatr. Genet. 2005; 15:71-75. [PubMed: 15722961]

Ehlers CL, Wilhelmsen KC. Genomic screen for substance dependence and body mass index in Southwest California Indians. Genes Brain Behav. 2007; 6:184-191. [PubMed: 16764678]

Faul F, Erdfelder E, Lang AG, Buchner A. G*Power 3: a flexible statistical power analysis program for the social, behavioral, and biomedical sciences. Behav. Res. Methods. 2007; 39:175-191. [PubMed: 17695343]

Faul F, Erdfelder E, Buchner A, Lang AG. Statistical power analyses using G*Power 3.1: tests for correlation and regression analyses. Behav. Res. Methods. 2009; 41:1149-1160. [PubMed: 19897823]

G*Power, Heinrich Heine University. G*Power version 3.1.9.2 for Mac OSX. Düsseldorf; Germany: Retrieved from http://www.gpower.hhu.de/en.html [Accessed 9/1/15]

Gilder DA, Lau P, Dixon M, Corey L, Phillips E, Ehlers CL. Co-morbidity of select anxiety, affective, and psychotic disorders with cannabis dependence in Southwest California Indians. J. Addict. Dis. 2006; 25:67-79. [PubMed: 17088227]

Gilder DA, Lau P, Corey L, Ehlers CL. Factors associated with remission from cannabis dependence in southwest California Indians. J. Addict. Dis. 2007; 26:23-30. [PubMed: 18032229]

Gilder DA, Lau P, Corey L, Ehlers CL. Factors associated with remission from alcohol dependence in an American Indian community group. Am. J. Psychiatry. 2008; 165:1172-1178. [PubMed: 18519526]

Gilder DA, Lau P, Ehlers CL. Item response theory analysis of lifetime cannabis-use disorder symptom severity in an American Indian community sample. J. Stud. Alcohol Drugs. 2009; 70:839-849. [PubMed: 19895760]

Gilder DA, Gizer IR, Lau P, Ehlers CL. Stimulant dependence and stimulant-associated psychosis: clinical characteristics and age of onset in a Native American community sample. J. Addict. Med. 2014; 8:241-248. [PubMed: 24755633]

Gilder DA, Wall TL, Ehlers CL. Comorbidity of select anxiety and affective disorders with alcohol dependence in Southwest California Indians. Alcohol. Clin. Exp. Res. 2004; 28:1805-1813. [PubMed: 15608596]

Gizer IR, Edenberg HJ, Gilder DA, Wilhelmsen KC, Ehlers CL. Association of alcohol dehydrogenase genes with alcohol-related phenotypes in a Native American community sample. Alcohol. Clin. Exp. Res. 2011; 35:2008-2018. [PubMed: 21635275]

Goldstein RB, Compton WM, Pulay AJ, Ruan WJ, Pickering RP, Stinson FS, Grant BF. Antisocial behavioral syndromes and DSM-IV drug use disorders in the United States: results from the 
National Epidemiologic Survey on Alcohol and Related Conditions. Drug Alcohol Depend. 2007; 90:145-158. [PubMed: 17433571]

Goldstein RB, Dawson DA, Chou SP, Ruan WJ, Saha TD, Pickering RP, Stinson FS, Grant BF. Antisocial behavioral syndromes and past-year physical health among adults in the United States: results from the National Epidemiologic Survey on Alcohol and Related Conditions. J. Clin. Psychiatry. 2008; 69:368-380. [PubMed: 18348594]

Goldstein RB, Dawson DA, Smith SM, Grant BF. Antisocial behavioral syndromes and 3-year qualityof-life outcomes in United States adults. Acta Psychiatr. Scand. 2012; 126:137-150. [PubMed: 22375904]

Grant BF, Dawson DA, Stinson FS, Chou SP, Dufour MC, Pickering RP. The 12-month prevalence and trends in DSM-IV alcohol abuse and dependence: United States, 1991-1992 and 2001-2002. Drug Alcohol Depend. 2004; 74:223-234. [PubMed: 15194200]

Grant BF, Goldstein RB, Saha TD, Chou SP, Jung J, Zhang H, Pickering RP, Ruan WJ, Smith SM, Huang B, Hasin DS. Epidemiology of DSM-5 Alcohol Use Disorder: results From the National Epidemiologic Survey on Alcohol and Related Conditions III. JAMA Psychiatry. 2015; 72:757766. [PubMed: 26039070]

Hasin DS, Stinson FS, Ogburn E, Grant BF. Prevalence, correlates, disability, and comorbidity of DSM-IV alcohol abuse and dependence in the United States: results from the National Epidemiologic Survey on Alcohol and Related Conditions. Arch. Gen. Psychiatry. 2007; 64:830842. [PubMed: 17606817]

Hesselbrock M, Easton C, Bucholz KK, Schuckit, Hesselbrock V. A validity study of the SSAGA--a comparison with the SCAN. Addiction. 1999; 94:1361-1370. [PubMed: 10615721]

Hesselbrock MN, Hesselbrock VM, Segal B, Schuckit MA, Bucholz K. Ethnicity and psychiatric comorbidity among alcohol-dependent persons who receive inpatient treatment: African Americans, Alaska Natives, Caucasians, and Hispanics. Alcohol. Clin. Exp. Res. 2003; 27:13681373. [PubMed: 12966342]

Hesselbrock VM, Segal B, Hesselbrock MN. Alcohol dependence among Alaska Natives entering alcoholism treatment: a gender comparison. J. Stud. Alcohol. 2000; 61:150-156. [PubMed: 10627109]

Hingson RW, Heeren T, Winter MR. Age at drinking onset and alcohol dependence: age at onset, duration, and severity. Arch. Pediatr. Adolesc. Med. 2006; 160:739-746. [PubMed: 16818840]

Indian Health Service. Trends in Indian Health 2002-2003 Edition. Indian Health Service, U.S. Department of Health and Human Services; Rockville, MD: 2009. Retrieved from https:// www.ihs.gov/dps/index.cfm/publications/trends03/ [Accessed 9.3.15]

Indian Health Service. Trends in Indian Health 2014 Edition. Indian Health Service, U.S. Department of Health and Human Services; Rockville, MD: 2015. Retrieved from https://www.ihs.gov/dps/ index.cfm/publications/trends2014/ [Accessed 9.3.15]

Kessler RC, Crum RM, Warner LA, Nelson CB, Schulenberg J, Anthony JC. Lifetime co-occurrence of DSM-III-R alcohol abuse and dependence with other psychiatric disorders in the National Comorbidity Survey. Arch. Gen. Psychiatry. 1997; 54:313-321. [PubMed: 9107147]

Kunitz SJ. Risk factors for polydrug use in a Native American population. Subst. Use. Misuse. 2008; 43:331-339. [PubMed: 18365935]

Landen M, Roeber J, Naimi T, Nielsen L, Sewell M. Alcohol-attributable mortality among American Indians and Alaska Natives in the United States, 1999-2009. Am. J. Public Health. 2014; 104(Suppl 3):S343-S349. [PubMed: 24754661]

Leung PK, Kinzie JD, Boehnlein JK, Shore JH. A prospective study of the natural course of alcoholism in a Native American village. J. Stud. Alcohol. 1993; 54:733-738. [PubMed: 8271810]

Malcolm BP, Hesselbrock MN, Segal B. Multiple substance dependence and course of alcoholism among Alaska native men and women. Subst. Use Misuse. 2006; 41:729-741. [PubMed: 16603457]

Moss HB, Chen CM, Yi HY. Subtypes of alcohol dependence in a nationally representative sample. Drug Alcohol Depend. 2007; 91:149-158. [PubMed: 17597309]

Moss HB, Chen CM, Yi HY. Prospective follow-up of empirically derived Alcohol Dependence subtypes in wave 2 of the National Epidemiologic Survey on Alcohol And Related Conditions 
(NESARC): recovery status, alcohol use disorders and diagnostic criteria, alcohol consumption behavior, health status, and treatment seeking. Alcohol. Clin. Exp. Res. 2010; 34:1073-1083. [PubMed: 20374206]

Moss HB, Chen CM, Yi HY. Early adolescent patterns of alcohol, cigarettes, and marijuana polysubstance use and young adult substance use outcomes in a nationally representative sample. Drug Alcohol Depend. 2014; 136:51-62. [PubMed: 24434016]

Moss HB, Goldstein RB, Chen CM, Yi HY. Patterns of use of other drugs among those with alcohol dependence: Associations with drinking behavior and psychopathology. Addict. Behav. 2015; 50:192-198. [PubMed: 26151585]

Robin RW, Long JC, Rasmussen JK, Albaugh B, Goldman D. Relationship of binge drinking to alcohol dependence, other psychiatric disorders, and behavioral problems in an American Indian tribe. Alcohol. Clin. Exp. Res. 1998; 22:518-523. [PubMed: 9581662]

Schuckit MA, Anthenelli RM, Bucholz KK, Hesselbrock VM, Tipp J. The time course of development of alcohol-related problems in men and women. J. Stud. Alcohol. 1995; 56:218-225. [PubMed: 7760569]

Schuckit MA, Smith TL, Anthenelli R, Irwin M. Clinical course of alcoholism in 636 male inpatients. Am. J. Psychiatry. 1993; 150:786-792. [PubMed: 8480826]

Schuckit MA, Smith TL, Danko GP, Reich T, Bucholz KK, Bierut LJ. Similarities in the clinical characteristics related to alcohol dependence in two populations. Am. J. Addict. 2002; 11:1-9. [PubMed: 11876579]

Scott DM, Williams CD, Cain GE, Kwagyan J, Kalu N, Ehlers CL, Hesselbrock V, Taylor RE. Clinical course of alcohol dependence in African Americans. J. Addict. Dis. 2008; 27:43-50. [PubMed: 19042590]

SPSS software. IBM SPSS Statistics for Macintosh. Version 20.0. Armonk, NY:

Smith SM, Stinson FS, Dawson DA, Goldstein R, Huang B, Grant BF. Race/ethnic differences in the prevalence and co-occurrence of substance use disorders and independent mood and anxiety disorders: Results from the National Epidemiologic Survey on Alcohol and Related Conditions. Psychol. Med. 2006; 36:987-998. [PubMed: 16650344]

Spear LP, Swartzwelder HS. Adolescent alcohol exposure and persistence of adolescent-typical phenotypes into adulthood: a mini-review. Neurosci. Biobehav. Rev. 2014; 45:1-8. [PubMed: 24813805]

Spicer P, Beals J, Croy CD, Mitchell CM, Novins DK, Moore L, Manson SM. The prevalence of DSM-III-R alcohol dependence in two American Indian populations. Alcohol. Clin. Exp. Res. 2003; 27:1785-1797. [PubMed: 14634495]

Stanley LR, Harness SD, Swaim RC, Beauvais F. Rates of substance use of American Indian students in 8th, 10th, and 12th grades living on or near reservations: update, 2009-2012. Public Health Rep. 2014; 129:156-163. [PubMed: 24587550]

Statistics Solutions. [Accessed 12/3/15] Statistics Solutions Professional (Version 1.14.12.29) [Computer software]. 2014. Retrieved from http://ssp.statisticssolutions.com/spearmancorrelation-2-tailed/

StatsToDo Trading Pty Ltd.. [Accessed 12/3/15] StatsToDo [Computer software]. Computer Program to Calculate Sample Size Requirement for Log Rank Test in Survival Analysis Using Censored Data. 2013. Retrieved from https://www.statstodo.com/SSizSurvival_Pgm.php

Sum, A.; Khatiwada, I.; McLaughlin, J. The consequences of dropping out of high school: joblessness and jailing for high school dropouts and the high cost to taxpayers. Center for Labor Market Studies Publications, Northeastern University; Boston, MA: 2009. Paper 23

Swift W, Coffey C, Carlin JB, Degenhardt L, Patton GC. Adolescent cannabis users at 24 years: trajectories to regular weekly use and dependence in young adulthood. Addiction. 2008; 103:1361-1370. [PubMed: 18855826]

Townsend L, Flisher AJ, King G. A systematic review of the relationship between high school dropout and substance use. Clin. Child Fam. Psychol. Rev. 2007; 10:295-317. [PubMed: 17636403]

U.S. Census Bureau. [Accessed 10/30/15] American Community Survey 5-Year Estimates; using American FactFinder. 2010a. Retrieved from http://factfinder2.census.gov 
U.S. Census Bureau. [Accessed 10/30/15] Census, Summary File 1; using American FactFinder. 2010b. Retrieved from http://factfinder2.census.gov

Wall TL, Carr LG, Ehlers CL. Protective association of genetic variation in alcohol dehydrogenase with alcohol dependence in Native American Mission Indians. Am. J. Psychiatry. 2003; 160:4146. [PubMed: 12505800]

Whitesell NR, Beals J, Crow CB, Mitchell CM, Novins DK. Epidemiology and etiology of substance use among American Indians and Alaska Natives: risk, protection, and implications for prevention. Am. J. Drug Alcohol Abuse. 2012; 38:376-382. [PubMed: 22931069]

Wilhelmsen KC, Ehlers C. Heritability of substance dependence in a Native American population. Psychiatr. Genet. 2005; 15:101-107. [PubMed: 15900224]

Wu LT, Schlenger WE. Psychostimulant dependence in a community sample. Subst. Use. Misuse. 2003; 38:221-248. [PubMed: 12625429] 


\section{HIGHLIGHTS}

Multi-substance use disorder was more prevalent than single use disorder.

Alcohol was the most common drug followed by stimulants and cannabis.

Multi-substance use disorder was more severe and had greater co-morbidity. 


\section{Table 1}

Demographic variables of participants according to substance use disorder category - No Substance Use Disorder (No SUD), Alcohol Use Disorder (AUD) alone, and Multi-Substance Use Disorder (MSUD)

\begin{tabular}{|c|c|c|c|c|}
\hline $\begin{array}{l}\text { Demographic or } \\
\text { clinical variable }\end{array}$ & $\begin{array}{l}\text { Overall } \\
\text { p-value }\end{array}$ & $\begin{array}{c}\text { No } \\
\text { SUD } \\
\mathbf{n}=\mathbf{3 4 7}\end{array}$ & $\begin{array}{c}\text { AUD } \\
\text { alone } \\
\mathrm{n}=146\end{array}$ & $\begin{array}{l}\text { MSUD } \\
n=284\end{array}$ \\
\hline & & Mean (SE) & Mean (SE) & Mean (SE) \\
\hline Age at interview & .953 & $31.3(0.8)$ & $31.6(1.0)$ & $31.2(0.6)$ \\
\hline \multirow[t]{2}{*}{ Years of education } & $<.001$ & $11.8(0.1)$ & $11.8(0.1)$ & $11.3(0.1)^{a b}$ \\
\hline & & $\underline{\mathrm{n}(\%)}$ & $\underline{\mathrm{n}(\%)}$ & $\underline{\mathrm{n}(\%)}$ \\
\hline \multicolumn{5}{|l|}{ Gender } \\
\hline Male & .002 & $124(35.7)$ & $72(49.3)^{c}$ & $135(47.5)^{d}$ \\
\hline \multicolumn{5}{|l|}{ Annual Income } \\
\hline \multicolumn{5}{|l|}{$<\$ 20,000$} \\
\hline Yes & .013 & $121(38.3)$ & $64(45.7)$ & $135(50.4)^{e}$ \\
\hline \multicolumn{5}{|l|}{ Employed } \\
\hline Yes & .043 & $138(40.6)$ & $63(43.2)$ & $88(32.4)$ \\
\hline \multicolumn{5}{|l|}{ Married } \\
\hline Yes & .364 & $56(16.2)$ & $18(12.3)$ & $50(17.6)$ \\
\hline \multicolumn{5}{|l|}{$\mathrm{NAH} \geq 50 \%$} \\
\hline Yes & .052 & $127(36.6)$ & $64(43.8)$ & $130(45.8)$ \\
\hline \multicolumn{5}{|l|}{ High School Dropout } \\
\hline Yes & $<.001$ & 141 (40.6) & $60(41.4)$ & $172(60.6)^{f g}$ \\
\hline
\end{tabular}

$a_{\mathrm{p}<.01 \text { MSUD vs. No SUD, } \mathrm{F}(1,629)=20.2 \text {; }}$

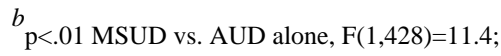

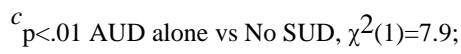

$d_{\mathrm{p}<.01 \text { MSUD vs. No SUD, } \chi^{2}(1)=9.0 \text {; }}$

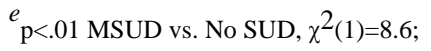

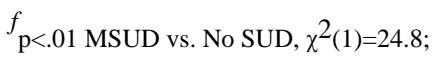

$g_{\mathrm{p}<.01 \text { MSUD vs. AUD alone, } \chi^{2}(1)=14.2}$

Demographic variables are presented according to the three substance use disorder categories: No SUD, AUD alone and MSUD. The overall pvalues reported are Pearson Chi-Square for categorical variables and ANOVA for continuous variables. Substance use disorder categories were then compared in pairs using Fisher's Exact test for dichotomous variables and ANOVA for continuous variables, with significance set at $p<.01$. 


\section{Table 2}

Clinical variables of participants according to substance use disorder category - No Substance Use Disorder (No SUD), Alcohol Use Disorder (AUD) alone, and Multi-substance Use Disorder (MSUD)

\begin{tabular}{lcccc} 
Clinical variable & $\begin{array}{c}\text { Overall } \\
\text { p-value }\end{array}$ & $\begin{array}{c}\text { No } \\
\text { SUD } \\
\mathbf{n}=\mathbf{3 4 7}\end{array}$ & $\begin{array}{c}\text { AUD } \\
\text { alone } \\
\mathbf{n = 1 4 6}\end{array}$ & $\begin{array}{c}\text { MSUD } \\
\mathbf{n = 2 8 4}\end{array}$ \\
\hline $\begin{array}{l}\text { Any affective disorder } \\
\quad \text { Yes }\end{array}$ & & $\underline{\mathrm{n}(\%)}$ & $\underline{\mathrm{n}(\%)}$ \\
$\begin{array}{l}\text { Any anxiety disorder } \\
\text { Yes }\end{array}$ & .015 & $77(22.2)$ & $41(28.1)$ & $92(32.4)^{a}$ \\
$\begin{array}{l}\text { ASPD or CD } \\
\text { Yes }\end{array}$ & .483 & $58(16.7)$ & $24(16.4)$ & $57(20.1)$ \\
ADHD & $<.001$ & $28(8.1)$ & $21(14.4)$ & $91(32.0)^{b c}$ \\
$\quad$ Yes & & & & \\
\hline
\end{tabular}

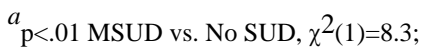

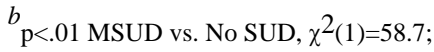

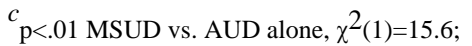

$d_{\mathrm{p}<.01 \text { MSUD vs. No SUD, } \chi^{2}(1)=19.1}$

Clinical variables are presented according to the three substance use disorder categories: No SUD, AUD alone and MSUD. The overall p-values reported are Pearson Chi-Square. Substance use disorder categories were then compared in pairs using Fisher's Exact test, with significance set at $\mathrm{p}<.01$. 


\section{Table 3}

Age of first intoxication with alcohol, age of first cannabis and stimulant use, and age onset of dependence variables of participants according to substance use disorder category - No Substance Use Disorder (No SUD), Alcohol Use Disorder (AUD) alone, and Multi-Substance Use Disorder (MSUD)

\begin{tabular}{|c|c|c|c|c|}
\hline Substance use variable & $\begin{array}{l}\text { Overall } \\
\text { p-value }\end{array}$ & $\begin{array}{c}\text { No } \\
\text { SUD } \\
\mathbf{n}=\mathbf{3 4 7}\end{array}$ & $\begin{array}{c}\text { AUD } \\
\text { alone } \\
n=146\end{array}$ & $\begin{array}{c}\text { MSUD } \\
\mathrm{n}=284\end{array}$ \\
\hline & & Mean (SE) & Mean (SE) & Mean (SE) \\
\hline Age of first intoxication (yrs) & $<.001$ & $17.4(0.2)$ & $15.2(0.3)^{a}$ & $13.8(0.2)^{b c}$ \\
\hline Age of first cannabis use & $<.001$ & $16.9(0.4)$ & $15.8(0.4)$ & $13.8(0.2)^{d e}$ \\
\hline Age of first stimulant use & .002 & $20.1(0.5)$ & $20.4(0.8)$ & $18.1(0.4)^{f g}$ \\
\hline Age onset alcohol use disorder & $<.001$ & N/A & $21.1(0.5)$ & $19.2(0.3)^{h}$ \\
\hline Age onset cannabis use disorder & N/A & N/A & N/A & $17.4(0.4)$ \\
\hline Age onset stimulant use disorder & $\mathrm{N} / \mathrm{A}$ & N/A & N/A & $20.5(0.5)$ \\
\hline \multicolumn{5}{|c|}{$a_{\mathrm{p}<.01}$ AUD alone vs. No SUD, $\mathrm{F}(1,429)=28.6$} \\
\hline \multicolumn{5}{|c|}{${ }^{b} \mathrm{p}<.01$ MSUD vs. No SUD, F $(1,565)=139.8$} \\
\hline \multicolumn{5}{|c|}{$c^{c}<.01$ MSUD vs. AUD alone, $F(1,426)=16.2$} \\
\hline \multicolumn{5}{|c|}{ 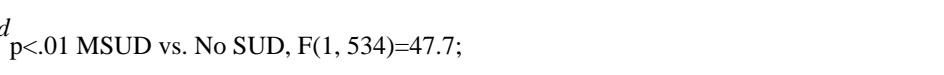 } \\
\hline \multicolumn{5}{|c|}{$e_{p}^{e}<.01$ MSUD vs. AUD alone, $\mathrm{F}(1,406)=24.9$} \\
\hline \multicolumn{5}{|c|}{ 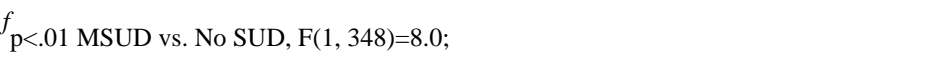 } \\
\hline \multicolumn{5}{|c|}{ 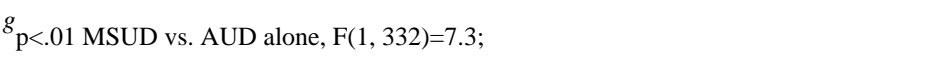 } \\
\hline \multicolumn{5}{|c|}{$h_{\mathrm{p}<.01 \text { MSUD vs. AUD alone, } \mathrm{F}(1,428)=12.4}$} \\
\hline
\end{tabular}

